ANDRÉS FELIPE CASTELAR

JENNY ALEXANDRA LOZANO GARCÍA*

Universidad Icesi (Cali, Colombia)

\title{
Reconocimiento de la diversidad sexual en la escuela: algunas paradojas ${ }^{* *}$
}

\author{
Recognition of Sexual Diversity in Schools: \\ Some Paradoxes
}

Reconhecimento da diversidade sexual na escola:

Alguns paradoxos

* Psicóloga egresada de la Universidad Icesi y especialista en psicología clínica. https://orcid.org/oooo-ooo1-8292-3180. Correo electrónico: jenny.lozano27@gmail.com

** Este artículo de reflexión surge en el marco de la investigación «Diversidad sexual en la escuela: una mirada desde los profesores», realizado en 2014. Artículo de investigación recibido el o7-06-2016 y aceptado 22-08-2016. 


\section{Cómo citar}

Castelar, A. F. y Lozano García, J. A. (2018).

Reconocimiento de la diversidad sexual en la escuela:

algunas paradojas. CS, (25), 51-79.

DOI: http://dx.doi.org/10.18046/recs.i25.2220 


\section{Resumen}

Abstract

Resumo

El presente artículo analiza el nivel de reconocimiento de la diversidad sexual y de género en el contexto educativo; tomando el espacio escolar como institución que forma a sujetos desde una uniformidad de conocimientos y de conductas esperadas. Para ello, se exploran las «teorías» que surgen en los docentes de una institución pública de la ciudad de Cali (Colombia) para explicarse la diversidad sexual, comprendida como los sucesos que vienen a interrumpir la estabilidad institucional, y comprender las posiciones que estos docentes toman frente a la identidad sexual de sus estudiantes.

PALABRAS CLAVE:

Contexto educativo diversidad sexual, docentes, género, reconocimiento

This article analyzes the level of recognition of sexual and gender diversity within an educational context; taking the school as an institution that trains subjects from a uniformity of knowledge and expected behaviors. To accomplish this, it explores the «theories» that arise in the teachers of one public school in Cali, Colombia to explain sexual diversity, understood as events that come to interrupt institutional stability, and seeks to understand the positions they take with regard to the sexual identity of the students.

\section{KEYWORDS:}

Educational context, Sexual diversity, Teachers, Gender, Recognition

O presente artigo analisa o nível de reconhecimento da diversidade sexual e do gênero no contexto educativo; tomando o espaço como instituição que forma a sujeitos de uma uniformidade de conhecimentos e de condutas esperadas. Para isso, se exploram as 
«teorias» que surgem nos docentes de uma instituição pública da cidade de Cali (Colômbia) para explicar-se a diversidade sexual, compreendidos como sucedidos que vem a interromper a estabilidade institucional e compreender as posições que estes tomam diante da identidade sexual de seus estudantes.

PALAVRAS CHAVE:

Contexto educativo, diversidade sexual, docentes, gênero, reconhecimento 


\section{Introducción}

Una de las preocupaciones actuales de la escuela es el fomento de la convivencia entre sus distintos actores. Tema que ha ganado espacio en la agenda política de la educación desde la década del setenta, con los trabajos críticos de Illich (1971). ${ }^{1}$ Algunas políticas y disposiciones gubernamentales apuntan a hacer de las instituciones educativas de hoy territorios de paz, en los que los actores comprometidos en el proceso educativo sean capaces de resolver los distintos problemas y crisis que se presentan en ellas. El conflicto pasa a ser reconocido como parte de la condición humana, por lo que la escuela tendría que tramitarlo más que silenciarlo.

El esquema tradicional de la escuela encargada de la trasmisión de ideales, valores y cultura, en la que el control de los cuerpos imponía rigidez, los espacios de encuentro estaban delimitados y el conflicto se ocultaba o se excluía, ha dado paso a una flexibilización progresiva donde las relaciones de enseñanza-aprendizaje están permeadas por la promoción del reconocimiento: ya sea de las diferencias en los estilos de aprendizaje, en las necesidades educativas o en los modos de relación. Lentamente, la institución escolar ha cedido en sus tendencias homogeneizantes. Ello se debe, en buena medida, a la aparición de estrategias pedagógicas como la Escuela Nueva, el uso de las tecnologías de información y comunicación en el proceso educativo y de discursos alternativos sobre la educación ${ }^{2}$, así como a la actualización de las leyes que regulan la práctica docente. Con la intervención de leyes estatales, de políticas gubernamentales, de políticas de gestión de la calidad y de la socialización de resultados de investigaciones, etc., el elenco de actores vinculados al proceso formativo se amplía. En adelante, la relación docente-estudiante será acompañada (supervisada) no solo por directivas y padres de familia, sino por normativas, decretos y criterios políticos que influencian a los tomadores de decisiones y generan transformaciones significativas en la institución educativa.

1. En Colombia se da la construcción de la «Ley de convivencia escolar» (Ley 1620 de 2013). En ella se establece el Sistema Nacional de Convivencia Escolar y formación para el ejercicio de los Derechos Humanos, la Educación para la Sexualidad y la Prevención y Mitigación de la Violencia Escolar. Esta ley busca unificar la reglamentación de los manuales de convivencia a partir de los comités nacional, departamental, distrital y municipal de convivencia; también incluye una Ruta de Atención Integral para la Convivencia Escolar que promueve la construcción de iniciativas de formación en temáticas de Derechos humanos, sexuales y reproductivos, sexualidad, competencias ciudadanas, entre otros.

2. El documental independiente «La Educación Prohibida» (Doin, 2012) constituye una crítica a la escuela tradicional, y muestra desde diferentes posturas pedagógicas una preocupación central por la educación del ser, antes que del saber. 
Piénsese, por ejemplo, en los modos de concebir la diversidad sexual en el aula y en la escuela, como la homosexualidad ${ }^{3} \mathrm{o}$ las expresiones de una masculinidad no hegemónica. Si antes era considerada un problema disciplinario, motivo de sanciones graves o una falta grave en la conducta, empieza a ser reconocida de forma paulatina como un modo de vida alternativo, expresión del libre desarrollo de la personalidad y, por tanto, un derecho tutelado por la ley. En ese orden de ideas, esta polifonía de voces sobre los distintos modos de educar, de gestionar la convivencia en el aula y de comprender al otro, es generadora de tensiones que tendrían que ser conciliadas frente al quehacer profesional, las actividades laborales y las exigencias legales presentes en el entramado institucional. ${ }^{4} \mathrm{El}$ presente artículo analiza una tendencia en la resolución de esta tensión, específicamente en el caso de la diversidad sexual y de género ${ }^{5}$ en los entornos escolares: la formulación de teorías cerebrales ${ }^{6}$ para explicar el origen de las expresiones no hegemónicas de género de algunos estudiantes. ${ }^{7}$

3. La educación sexual en el ámbito educativo se inclina en gran parte hacia la prevención de riesgos como enfermedades de trasmisión sexual y embarazos no deseados. Sin embargo, hay reservas sobre la diversidad sexual, con el temor de que la exposición de orientaciones no hegemónicas, como la homosexualidad, derive en promoción de las mismas. La homosexualidad, comprendida como la orientación afectivo-erótica hacia una persona del mismo sexo, genera calificativos como «menos mujer»o «menos hombre» por trasgredir el ideal de familia tradicional (García Suarez, 2007). En el caso de la bisexualidad, algunos consideran incluso que no existe, pues la presión por definir una identidad usualmente implica definir un solo objeto de deseo y no preferir ambos (Clarke y Peel, 2007). En general, estas categorías resultan insuficientes para sostener la idea de diversidad, como se verá más adelante.

4. Por «convivencia en la escuela» se entiende el ideal social que fomenta la construcción de relaciones sociales positivas y proactivas en la comunidad académica, el empleo de estrategias eficaces para solucionar conflictos y la posibilidad de que sus actores sean considerados pares (nunca alguien superior o inferior) para no menoscabar su dignidad. El reglamento estudiantil (manual de convivencia), sobre el cual se rige cada institución, delimita los derechos y deberes de los actores de la institución. La convivencia se podría concebir como un ideal imposible debido a las particularidades de cada estudiante que interactúan en la escuela.

5. Nótese que no se habla de la «diferencia» sino de la diversidad. Si aquella presupone que existe un modelo o tipo a seguir o desde el cual se toma distancia, esta desestima la existencia de un modelo y fomenta la variación y la contingencia.

6. El término «teoría cerebral» trata de localizar el origen de la homosexualidad y de las expresiones de género no hegemónicas en algún punto del cerebro (idea anatómica) o a un desbalance hormonal (idea fisiológica). Si bien todas las conductas humanas tienen un asiento cerebral, lo que está en juego en las teorías etiológicas es el esfuerzo de comprensión del origen determinante del fenómeno. No se analizarán las teorías evolucionarias (que también están muy presentes hoy en el lenguaje cotidiano) que considerarían la homosexualidad como una estrategia de control poblacional de la especie humana (Buss, 1996).

7. Por «expresiones no hegemónicas de género» se piensa en aquellas conductas, prácticas y modos de presentación ante los otros que no se adecúan a las expectativas tradicionales sobre ser hombre o ser mujer, lo que no se vincula con la orientación sexual. 
En primer lugar, se caracteriza el lugar de la diversidad sexual y de género en el contexto educativo; luego se presentan algunas voces de profesores vinculados a una institución educativa pública de la ciudad de Santiago de Cali, entrevistados a lo largo del año $2014^{8}$, que tratan de dar sentido a aquello que, a su juicio, daría origen a la homosexualidad y a las expresiones de género no normativas en los adolescentes de hoy; posteriormente, se reflexiona sobre el sentido que tienen este tipo de elaboraciones para comprender la diversidad, a través de aportes de autores como Siri Hustvedt (2010; 2013) y Nikolas Rose (2013); al final, se caracterizan algunas paradojas que nacen de la difusión de estas teorías etiológicas en el reconocimiento de la diversidad en los espacios escolares, entre ellos los usos biopolíticos dados a las teorías cerebrales que analizan las diferencias entre los seres humanos.

\section{La diversidad de expresiones en la escuela}

El espacio educativo está constituido no solo para el aprendizaje de contenido académico, sino también como escenario de socialización. A partir de la Escuela Nueva se realizan enfoques educativos con mayor reconocimiento de la diversidad, no solo de los estudiantes, sino de los estilos de aprendizaje y enseñanza (Ministerio de Educación Nacional Colombiano - MEN, 2010); esto irrumpe con la normatividad de la educación colombiana fuertemente influenciada por cánones religiosos (católicos jesuitas), que determinan una visión del estudiante: «ética, religiosa, cognitiva, afectiva, estética, psicomotriz y social» (Reyes, 2013:144). Estos diferentes discursos son puestos en tensión cuando se presentan manifestaciones por parte de los estudiantes que van en contra de la uniformidad y ponen en cuestionamiento la autoridad escolar.

En agosto de 2014, Sergio Urrego, un estudiante de grado 11º, se arrojó al vacío desde lo alto de un centro comercial de la ciudad de Bogotá; al día siguiente le fue declarada muerte cerebral. Se cerraba así un capítulo trágico que empezó en junio del mismo año en una de las clases del colegio Gimnasio Castillo Campestre, en el que estudiaba, cuando su profesor le decomisó su teléfono celular y vio unas fotos en que se besaba con su novio; por esto, le hizo un llamado de atención y dio inicio a un proceso de sanción escolar que implicó:

- La prohibición de tener manifestaciones amorosas en público;

- Ser obligados por la institución a revelar su orientación sexual a un grupo de profesores (que actuaban como testigos) y luego, en casa, a hacerlo con sus padres;

8. Estas entrevistas hacen parte de la investigación adelantada en 2014 por la estudiante Jenny Lozano, como parte de su trabajo de grado para aspirar al título de psicóloga, en la Universidad Icesi, y que lleva por nombre «Diversidad sexual en la escuela». 
- Buscar acompañamiento psicológico obligatorio y certificar la asistencia al mismo, so pena de no poder continuar con sus estudios; y

- En el caso de Sergio y sus padres, enfrentar una denuncia por acoso sexual impuesta por los padres de su novio en la Fiscalía General de la Nación (aparentemente bajo presión del colegio).

La rectora de la institución, profesora Amanda Castillo, reaccionó de manera bastante negativa ante el caso de Sergio, lo tachó de «ateo, anarco y homosexual» (en su cuenta de Facebook, Sergio pertenecía a un grupo de estudios libertarios) y sostuvo con él continuos enfrentamientos verbales. En declaración escrita a una comisaría de familia de Bogotá, expresó:

Nuestro estudiante Sergio Urrego no ha recibido una adecuada orientación sexual de sus padres, evidentemente tiene plena libertad de consultar internet, libros, videos, películas, todo tipo de material pornográfico, perjudicial, no apto para su edad, desviando su orientación sexual, declarándose bisexual públicamente. (Sergio sífue discriminado, septiembre 25 de 2014).

Este caso despertó el interés de la opinión pública en septiembre de 2014, pues la madre de Sergio inició un proceso jurídico contra la institución para tutelar el derecho al buen nombre y a la honra de su hijo fallecido. Se ponía en evidencia la dificultad de algunas entidades escolares (y, por qué no, de la escuela misma como institución) para reconocer y admitir la diversidad sexual y de géneros. La rectora, en este caso, consideraría que la homosexualidad es una conducta problemática y negativa que debió ser corregida a tiempo por el núcleo familiar del joven ${ }^{9}$; por ello consideraba válido expulsar al adolescente del sistema educativo.

Sin entrar a analizar lo que la ley podría considerar un acto de discriminación y una violación a los derechos individuales, hay que preguntar por las razones que llevan a los docentes a seguir viendo la diversidad como un problema social que la familia, los medios o la ley colombiana han desatendido. Si bien los prejuicios tienen orígenes multicausales que no se pueden describir aquí, no hay que desconocer un fuerte componente institucional. ${ }^{10}$

9. En la declaración de la profesora Castillo hay quizás una confusión conceptual entre la orientación del deseo de Sergio y la orientación que ella esperaría que dieran las familias sobre cómo actuar en su escuela, es decir, sobre cómo asumir su sexualidad.

10. El dispositivo educativo tiene como fin la transmisión de prácticas y subjetividades, y de disciplinar el cuerpo. También cuenta con el poder para disciplinar individuos, con el fin de homogeneizarlos (Foucault, 2008). 
De acuerdo con el Artículo 46 del Decreto 2277 de 1979, el Régimen Disciplinario Docente colombiano consideraba como causal de mala conducta la comprobación de que un profesor incurriera en «el homosexualismo, o la práctica de aberraciones sexuales» (literal b). Tal medida coincidía con la penalización de las conductas homosexuales en el Código Penal Colombiano (medida existente desde la década del treinta y que sancionaba con cárcel a las personas que expresaran formas de homosexualidad: norma revisada y eliminada del Código en 1980). La homosexualidad era punible, pues generaba escándalo y atentaba contra «la moral y las sanas costumbres». Por extensió»n, se podría suponer que una persona homosexual no debía estar en contacto con niños y adolescentes pues estos eran fácilmente impresionables o se podrían ver afectados negativamente, al ser testigos de una práctica socialmente impropia (Bustamante, 2008). ${ }^{11}$

Mientras la Constitución Política de 1991 generaba un cambio trascendental al garantizar el derecho a la igualdad y al libre desarrollo de la personalidad (lo que permitió el reconocimiento jurídico de la diversidad sexual), la mencionada norma prohibitiva de la homosexualidad en el trabajo docente solo fue declarada inconstitucional con la sentencia de tutela C-481 de 1998. De modo que solo desde hace 20 años la homosexualidad dejó de ser sancionada como falta grave en el cuerpo docente colombiano. Este oficio, junto con el de notario y militar, han sido las profesiones sobre las que recientemente se ha debatido y levantado la prohibición para que sean ejercidas por personas homosexuales (lo que no implica que no hubiesen homosexuales en estos gremios, sino que la normativa imponía el silencio sobre la orientación y la simulación de la propia expresión de género). Los procesos jurídicos emprendidos en la última década del siglo XX (en especial mecanismos de exigibilidad de derechos como las acciones de tutela) abrieron espacios para evitar que la homosexualidad o las expresiones no normativas de género siguieran siendo motivo de sanción.

Korinfeld, Levy y Rascovan nos recuerdan que «asistimos a una época de cambios culturales y sociales que han generado una crisis global. Una crisis que ha cuestionado nuestras certidumbres y ha modificado determinados instituidos sociales $»^{12}$ (citado en Averbuj, Bozzalla, Marina, Tarantino y Zaritzky, 2005: 74). Ello no implica que las actitudes negativas o los estereotipos que circulan sobre esta diversidad hayan llegado a su fin ni que las instituciones se hayan dejado permear por este cambio

11. Esta situación puede ayudar a entender por qué muchas personas educadas en esta generación (que a la sazón tendrían más de 40 años) son quienes más se han asimilado al modelo heterosexual dominante, negándose a asumir públicamente su orientación y, en ocasiones, rechazando cualquier forma de socialización de la diversidad sexual.

12. Cursivas en el original. 
de perspectiva. ${ }^{13} \mathrm{Si}$ bien es cierto que hay contribuciones significativas recientes en el campo de la diversidad sensorial y motriz o en las necesidades educativas especiales, el tema de la diversidad sexual y de género en el aula apenas empieza a incluirse en esta agenda.

Por ejemplo, las reflexiones realizadas sobre el lugar del género en el espacio escolar se han centrado en el paulatino posicionamiento de la mujer en la escuela, mientras que otras formas de diversidad hacen parte de procesos investigativos periféricos. De hecho, se hace necesario generar una reflexión amplia sobre el papel de la mujer como uno de los paradigmas de la alteridad, en clave de la afirmación de Simone de Beauvoir (1949), según la cual la mujer sería la alteridad absoluta.

La diversidad de género empieza con la presencia misma de la mujer, quien vive su cuerpo de modo distinto al tradicional del varón, pero que se tiene que adecuar a un mundo claramente masculino, como el de la educación. Al tiempo, sus necesidades específicas solamente son atendidas en forma de demandas frente al riesgo de embarazo temprano. Explica Dolors Renau (1998): «Haciendo una estadística de las peticiones que formulan los maestros, nos damos cuenta de que por lo menos un $75 \%$ van orientadas a las conductas de los 'varones'. Y ello porque estos intervienen activamente en los alborotos y en las riñas. Pero existe un importante silencio: aquel que se refiere a las niñas» (92). La demanda profesoral se centra en las alteraciones visibles del orden, encabezadas por los varones. ${ }^{14}$

Por su parte, el trabajo de Erica Burman (1994) recurre a una perspectiva deconstruccionista para analizar el lugar ambiguo dado a la niña en el ámbito escolar: al atribuírsele una mayor dependencia frente al adulto. La niña como concepto se convierte en un problema sobre el cual hay que intervenir para evitar que la precocidad sexual y las dificultades en el aprendizaje frenaran el proceso «civilizatorio» de la escuela (Burman, 1994: 79 y ss.).

Pero ello no necesariamente hace de la escuela un espacio que replique los procesos sociales externos. En términos de clase social, por ejemplo, «los jóvenes que habitan circuitos de pobreza y permanecen en la escuela, encuentran allí una oportunidad de socialidad juvenil» (Duschatsky y Birgin, 2001: 86). En esa misma

13. En clave del concepto de Herbert Marcuse, se puede pensar que hoy en día hay una «tolerancia represiva» frente a la diversidad: se admite su existencia porque la ley así lo exige, pero no se la admite como un interlocutor válido, sino como una alteración del orden: de modo que se la tolera pero no se permite que se hable de ella, ni que se haga visible.

14. Como se verá, la masculinidad no hegemónica resulta mucho más problemática que la feminidad no hegemónica. Esto, antes que ser una ventaja para la condición femenina, habla más bien de la invisibilidad que violenta a las mujeres en espacios educativos. Si bien esta invisibilidad las protege de violencias explícitas, implica sufrir una desvalorización, al igual que un aislamiento por no tener un lugar legítimo en sociedad (Peixoto Caldas, Fonseca, Almeida y Almeida, 2012). 
línea, estos autores analizan la distinción de género-que deviene una jerarquía-en las escuelas de sectores populares argentinos:

Para las mujeres, ir a la escuela significa salir del lugar de lo doméstico. Recordemos que las chicas asumen la responsabilidad de las tareas hogareñas cuando sus madres [...] salen a trabajar. [...] Para los varones, asistir a la escuela significa en primer término una ruptura del estereotipo masculino [pues] sobrevive la idea del varón asociado a su capacidad de mando sobre la mujer y al ejercicio de una libertad vedada a ellas. Las barras de la esquina son masculinas, al [billar] pool juegan los varones y lo mismo ocurre con el fútbol. Por el contrario, la escuela propone condiciones en las que los géneros actúan simétricamente. (Duschatsky y Birgin, 2001: 84).

De modo que el espacio escolar puede operar y fomentar algunos procesos de cambio, ofreciendo una alternativa relacional entre los estudiantes y mejorando el vínculo de estos con los lazos simbólicos:

En la escuela tenemos una manera diferente de estar entre nosotros, podemos discutir, pensar distinto pero sin matarnos. La escuela es vivida por los jóvenes como el espacio fundador de una nueva socialidad marcada por la posibilidad de simbolizar las diferencias y despojarlas de un tono amenazador. (Duschatsky y Birgin, 2001: 85).

El sentido dado a la escuela no es el mismo en todos los estudiantes, pues no solo es un espacio para impartir conocimientos, sino que se puede convertir en alternativa para asumir el cuerpo y la corporalidad, así como para establecer relaciones con pares que ayuden a mediar en el desarrollo de la identidad. ${ }^{15} \mathrm{Y}$ si bien es cierto que la escuela, al ser una institución social que reproduce modelos identitarios, tiende a evitar o a minimizar los cambios, no por ello deja de ocupar un lugar de privilegio en la observación y seguimiento de estos. Sin embargo, esa prerrogativa no tendría que desvincular a los profesores de su rol de protagonistas del cambio, sino que, por el contrario, les invita a implicarse con los demás actores que intervienen en la escuela (estudiantes, padres de familia, etc.). Para los autores, la idea de «implicación» está relacionada con el compromiso del trabajo institucional (sea este consciente o inconsciente), tal como le ocurre a la persona que se deja afectar por los procesos y por las dinámicas que le comprometen (Korinfeld, Levy y Rascovan, citado en Averbuj et al., 2005: 75).

15. Ni qué decir entonces de aquellos jóvenes que no se reconocen en las expresiones de género hegemónicas y que viven la escuela no como un laboratorio personal que fortalece su identidad, sino como una suerte de prisión oficial que invisibiliza sus temores y menosprecia sus intentos por significar su cuerpo. 
Volviendo a Renau (1998), hay que recordar que el maestro es un profesional que:

- Debe producir un tipo de trabajo determinado;

- Es valorado, objetiva y subjetivamente por maestros, compañeros, padres y, a la postre, por él mismo;

- Está en unas determinadas condiciones laborales y físicas que facilitan, o no, su tarea;

- Está inmerso en una dinámica grupal e institucional con la que se identifica o no, con la que está en conflicto o con la que coopera;

- La propia institución se halla en un momento dado de su evolución dentro de la que las conductas toman su significado (85).

$\mathrm{Al}$ convertirse en receptor de múltiples exigencias, las expectativas sobre su desempeño óptimo llegan a niveles considerables. En el maestro recae la responsabilidad de formar buenos sujetos (teniendo en cuenta que la idea de «buen sujeto» varía de persona a persona) pero no se puede alejar de normativas y estrategias que evitan el cambio. Y es que:

Las escuelas son instituciones estructuradas de manera intrincada que sirven de receptáculos de sistemas simbólicos complejos. Ni absolutamente instituidas, lo que equivaldría a confundir el Estado de hecho con el de derecho, ni absolutamente instituyentes, lo que hará impensable una sociedad. (Duschatsky y Birgin, 2001: 107).

La escuela ha empezado a tomar conciencia de su papel en esta mediación, mas ello no implica que lo haya asumido del todo: aún pesan los afanes por imponer modos estándares de conducta y por sostener una única forma de vivir el cuerpo. Porque ¿qué ocurre cuando la implicación del docente es escasa o deficiente, en el peor de los casos? Korinfeld, Levy y Rascovan sostienen que los factores generadores de conflictos cotidianos son atribuidos a problemas aislados que se originarían en entornos ajenos al aula (malas condiciones de crianza, problemas de relación, etc.) y que perturban negativamente el desarrollo del proceso de aprendizaje y adaptación a la escuela. Pero no por ello se puede decir que el espacio escolar esté exento de conflictos ni de factores generadores de crisis: lo que ocurre es que estos no se visibilizan, sino que se ignoran de forma sistemática o existen en la medida en que operan como amenazas y riesgos por evitar. De esta forma, la escuela abandona una posibilidad preciosa de incluir el conflicto en sus procesos para permitir y fomentar el reconocimiento de la diversidad. Al silenciarla o ignorarla, esta se convierte más en un dolor de cabeza que en una oportunidad de cambio. 
El caso de la sexualidad es diciente. Si el tema aún es motivo de escándalo, la diversidad sexual (orientaciones sexuales que se enmarcan por fuera de lo heterosexual tradicional) y de géneros es vista como una alteración del orden, como una práctica generadora de conflictos y de crisis en los grupos y en las instituciones. De hecho, expresiones no hegemónicas de género y contactos sexuales no heterosexuales han sido motivo de sanción disciplinaria grave, es decir, de expulsión del sistema educativo. José R. Ubieto considera que cuando estas diferencias se hacen presentes, la injuria aparece como una estrategia de menosprecio social, pues «apunta a la identidad de ese sujeto que por su particularidad se opone (aunque sea involuntariamente) al conjunto» (citado en Goldenberg, 2011:36). Sin embargo, esto no implica que la sexualidad oficial esté igualmente ausente del ambiente educativo: las investigaciones etnográficas realizadas por Emma Renold (2005) en instituciones escolares, muestran cómo la heterosexualidad sigue siendo una norma que se vigila, se idealiza y se debe cumplir, pues se representa como un fenómeno naturalizado, sin historia. Hombres y mujeres asumen sus respectivos roles y se convierten en soportes de un único modelo de vivir las relaciones:

Este ethos familiar en el que las profesoras representan la posición idealizada de la benevolencia y el cuidado de la madre burguesa y los directores varones simbolizan al padre autoritario y duro, establecen un paralelismo al que con frecuencia se recurrirá para exponer y criticar las filosofías patriarcales de educación infantil. (Renold, 2005: 27). ${ }^{16}$

Que no se hable de sexualidad en la escuela no quiere decir que esta no se haga presente y permee las esferas de aprendizaje, al ser un factor organizador de roles y tareas diferenciadas en clave de género. Dice Renold:

Sólo recientemente la sexualidad ha sido abordada de forma explícita, como una presencia normalizante e invasiva al interior de la escuela primaria (véase Epstein y Johnson, 1998)... Amy Jo Wallis y VanEvery (2000) subrayan que ésta es un sitio sexual, tal como cualquier otra institución. La sexualidad y en particular, la heterosexualidad, en su opinión, «no sólo está presente, sino que es crucial para la organización de las escuelas primarias». (Renold, 2005: 26). ${ }^{17}$

En la actualidad, en las escuelas se manifiesta la preocupación de docentes y directivos por las nuevas expresiones de niños, niñas y jóvenes, pues el cambio en los

16. Traducción propia.

17. Traducción propia. 
modos tradicionales de acción resulta difícil de asimilar (como si estos no hubiesen hecho daño por generaciones); los modos usuales de presentarse ante el otro se ven como deteriorados; se ha observado una «crisis en la masculinidad [...] así como un aumento de los estilos viriles entre las féminas. Un dato interesante que aparece en varios de los informes recientes, es el hecho de que son los chicos los que manifiestan haber sufrido más abusos y vejaciones sexuales que las chicas» (Ubieto citado en Goldenberg, 2011:35). Hay que destacar cómo la diferencia de género es una pauta marcada por las anomalías que afecten a los varones: las alarmas se encienden si los chicos denuncian las irregularidades que los aquejan, pero no hay una sorpresa si las denuncias provienen de mujeres.

En 2016 fue publicado un informe sobre el clima escolar LGBT en Colombia, el cual puso en evidencia un interés marcado por reforzar los roles de género hegemónicos sobre los estudiantes en los colegios:

Los comentarios sobre estudiantes que no actúan de forma «suficientemente masculina» fueron más comunes que los comentarios sobre estudiantes que no actuaban de forma «suficientemente femenina». El $66.4 \%$ de los estudiantes oyó con frecuencia o siempre comentarios negativos sobre la «masculinidad» de los/las estudiantes, en comparación con el $54.1 \%$ que escuchó comentarios negativos con frecuencia o siempre sobre la «feminidad» de los/las estudiantes. (Sentiido y Colombia Diversa; 2016: 28).

De tal suerte que la diversidad en el campo de la escuela sí existe, pero bajo la forma de la amenaza, del riesgo de crisis, de la amenaza de injuria. Si la heterosexualidad es la norma, lo es en tanto que la homosexualidad, el afeminamiento (la pérdida de la virilidad) y la masculinización de la mujer (en forma de independencia, fuerza, agresión) no se produzcan. Pero ¿qué pasa cuando esta diversidad de conductas y expresiones no solamente existe, sino que se pasa a avalarlas jurídicamente y a exigir su reconocimiento pleno?

El reconocimiento es una estrategia que va más allá de los procesos jurídicos y fomenta el encuentro con el otro, celebrando la diferencia. Habría que advertir que el término «reconocimiento de la igualdad» es una contradicción en los términos. El reconocimiento hace existir, de suyo, la diferencia, borra los modelos y los objetos de comparación y hace existir la diversidad. Los procesos de reconocimiento se han fomentado en procesos sociales en los cuales se reivindica la justicia, en la política y en la intervención con grupos menospreciados (Fraser, 1997). En los entornos educativos, los procesos de reconocimiento también tienden a ser contradictorios, pues si bien los actores que se desempeñan en la escuela dependen el uno del otro para su constitución, no solo en lo académico, sino también en lo identitario, según Honneth dependen de «la aprobación normativa de los otros, porque sólo pueden 
validar sus aspiraciones y objetivos de orden práctico a partir de la reacción positiva de una contraparte» (citado por Hernàndez i Dobon, 2008).

Sin embargo, este no es el marco de aparición del reconocimiento como estrategia de convivencia. Este se convertiría en un problema y no en parte de la solución. Tal como lo plantea Castelar (2010), al reconocer la diferencia forzada desde una posición hegemónica, se fomenta la producción de una identidad colectiva (sustantivizada) que recoge los estereotipos que la configuran. La homosexualidad, caso ejemplar para pensar la diversidad, funciona como sinónimo de desorden y caos, como alteración de una naturaleza pacífica llamada heterosexualidad. En estos términos, el reconocimiento de la diversidad pasa por hacer existir a un cierto grupo, por denotar sus rasgos y por recordar los motivos de su padecimiento. El reconocimiento «es un recurso, un instrumento empleado por los mecanismos de poder: mediante el reconocimiento, la ideología se asienta en su capacidad productiva de sujetos. [...] Ser reconocido por el Estado es ser reconocido como un inferior» (Castelar, 2010: 208).

El espacio escolar, pensado en esta perspectiva como un entorno centrado en la modificación de las conductas, en la adecuación de los estudiantes en función de una buena ciudadanía y en la producción seriada de sujetos dóciles, es asumido como un campo de producción y entrenamiento en la heterosexualidad obligatoria, ${ }^{18}$ mientras que las distintas formas de diversidad en niños y niñas son desestimuladas o consideradas como alteraciones en el proceso educativo (Castelar, 2014):

Ya sea la normalización del género de las feminidades (hetero)sexualizadas o la flexibilización del género de las masculinidades (homo)sexualizadas, todos los roles de género (por ejemplo, «marimacho», «aburrido» $\mathrm{O}$ «mariquita») están, en cierta medida, sujetos a la mirada del varón heterosexual y todos son producidos en un marco heteronormativo de «heterosexualidad obligatoria». (Renold, 2005:35). 19

Es así donde el escenario educativo hace apropiación de nuevos discursos para explicarse estas manifestaciones de identidades de género no hegemónicas. Los discursos científicos, en especial las neurociencias, surgen como paradigmas que posibilitan la discusión sobre aquellos sucesos que se salen de lo «normal» (las

18. El concepto «heterosexualidad obligatoria» fue acuñado por la pensadora norteamericana Adrienne Rich (1980) para explicar las prácticas materiales y discursivas que legitiman y naturalizan una única forma (la heterosexual) de concebir el cuerpo y de pensar las relaciones de género, en las que los roles preexisten en función del dato sexual y los cuerpos tienen una misión específica: la mujer estaría destinada a la maternidad y a la reproducción de la familia. Estas prácticas responden a condiciones de poder que rigen sobre los cuerpos y controlan su sexualidad.

19. Traducción propia. 
dificultades de aprendizaje, por ejemplo) y la diversidad sexual. Se construye una producción discursiva de un cierto tipo de sujeto gracias a la ciencia, una búsqueda de causalidad y la posibilidad de reconocer al otro como un ser con necesidades especiales, debido a que sería anatómica o fisiológicamente distinto.

\section{Si la diversidad sexual es un asunto cerebral...}

Las teorías cerebrales de la sexualidad no son nuevas: en el panorama científico contemporáneo han gozado de un prestigio significativo, especialmente a fines de la década del sesenta y comienzos de los setenta, cuando los estudios realizados desde la embriología en bebés con ambigüedad genital permitieron trazar una distinción analítica entre los procesos anatómicos y fisiológicos (el desarrollo y la maduración cerebral y hormonal), de procesos sociales como el aprendizaje y la asignación de modelos y roles aprendidos de los padres y adultos (Luria, citado en: Katchadourian y Lunde, 1979): este último componente se conoce desde entonces como «género». La expresión social se podía explicar a partir del aprendizaje de modelos familiares y de la imposición de roles, pero no es tan sencillo entender la identidad sexual: esa certeza permanente de ser hombre o mujer que ya se puede examinar en niños de edad muy corta. La psiquiatría, interesada en clasificar las anomalías de la conducta sexual, diferenciaba la homosexualidad del travestismo y de la transexualidad, asignando el segundo a perturbaciones en la crianza, y al primero a alteraciones embriológicas tempranas (Luria, en: Katchadourian y Lunde, 1979: 220 y ss.). ${ }^{20}$

Se debe señalar, sin embargo, que la diversidad en el plano de la conducta sexual ha sido pensada como una alteración del orden heterosexual, y por esta razón la ciencia la ha considerado objeto de estudio. Si el origen de la diversidad es un asunto cerebral, es más factible entenderla y tolerar que se la defienda en los estrados judiciales. La ensayista norteamericana Siri Hustvedt lo explica en estos términos:

Puede que un día se resuelva el misterio genético de la esquizofrenia, pero por el momento continúa siendo una incógnita. Si un gemelo sufre esquizofrenia, existe un cincuenta por ciento de posibilidades de que el otro también la sufra. Es un porcentaje alto, pero no determinante. Tiene que darse la conjunción de otros factores, que pueden ser muy variados, desde la contaminación ambiental hasta la negligencia parental. Muchas veces la gente prefiere respuestas sencillas. En el clima cultural de hoy la frase

20. La medicina ha recurrido a múltiples estrategias, entre las que se incluyen la biología comparada (que estudia las conductas de los animales y las extrapola a humanos), los mencionados estudios con gemelos, además de estudios post-mortem y de comparaciones en el mapeo genético (Jones, 2012: 240 y ss.). 
trastorno mental orgánico tiene un efecto tranquilizador. Mi hijo no está loco. Lo que tiene es un problema en el cerebro. (Hustvedt, 2010: 23).

A continuación se presentan algunas ideas de profesores acerca del posible origen de la homosexualidad o de las expresiones no hegemónicas del género en sus estudiantes adolescentes. Estas fueron recopiladas a lo largo del año 2014 como parte de un trabajo sobre el reconocimiento de la diversidad en la escuela. Se han organizado en tres categorías: contexto social de aparición, origen y consecuencias. ${ }^{21}$

Para la profesora Liliana, de 41 años y profesora del área de Nuevas Tecnologías de la Información, las expresiones no hegemónicas de género se enmarcan en un momento histórico de libertad individual garantizado por la ley: «¿La diversidad sexual? A ver, estamos en una nueva época, donde sencillamente... por derecho constitucional podemos expresar nuestros afectos sin que haya prevención» (1-12:20).

Algo parecido sostiene Jorge, de 35 años y profesor del área de comunicación: «cuando escucho 'diversidad sexual' lo entiendo como libertad sexual, entonces pienso como en la libertad que tiene una persona a elegir sobre su sexualidad. La diversidad de ser hombre o la diversidad de ser mujer» (1-11:42). Llama la atención la idea de «elección» en este apartado, al notar que sus estudiantes tienen la posibilidad de decidir sobre su sexualidad. El profesor Jorge amplía su idea: «[...] Es algo de libertad sexual, es algo que lo hace sentir feliz, usted tiene la libertad de escoger algo que a usted lo llene y yo creo que sí, finalmente lo llena lo que culturalmente le han hecho creer a usted lo que es correcto, igualmente si tú tienes una personalidad contradictoria u opositora en oponerse lo que se ha establecido...» (1-11:56).

Así, el contexto actual ha permitido la aparición de nuevas expresiones de género, visibilizadas por el trabajo de colectivos LGBTI que buscan el reconocimiento de derechos individuales y colectivos (como la libre expresión, el libre desarrollo de la personalidad y la identidad) y quizás la visibilización de lo que antes era visto como prohibido o desviado, hace creer que hay una voluntad racional de «volverse homosexual», anulando así la posibilidad de libre albedrío o de elección sobre la homosexualidad. Es importante tener en cuenta este aspecto, pues pareciera que para los maestros las nuevas normativas y direccionamientos jurídicos fomentaran las libertades individuales y disminuyeran la calidad en las relaciones.

Por su parte, con respecto a las teorías que darían origen a la homosexualidad, la profesora Lucrecia explica:

21. Los registros de las afirmaciones de los profesores están presentados con su respectiva clave de localización en las grabaciones, así: número de entrevista, minutos, segundos. 
A ver, la homosexualidad nace, ¿̇en qué sentido? En que genéticamente, hormonalmente, el niño tiende a perder el cabo, entonces hay una tendencia al sexo opuesto y a las a-feminidades [sic]. ${ }^{22}$ Pero yo considero que también se hace porque cuando uno está en esa etapa de identificación sexual y ser imprudente que haya esa diversidad y sentir esa acción de sentir al otro, tiende a querer probar y en esa exploración sexual de una y otra manera se encuentra esa fuente de atracción y hay gente que se queda. Puede ser una niña delicada o un niño delicado pero consciente de su diversidad y de su toma de decisiones (1-12:51).

De modo que el cerebro es leído como maleable, modificable, una suerte de tabula rasa sexual, y el riesgo es «estancarse» en una fase de ese desarrollo y no continuar el proceso hasta alcanzar la heterosexualidad. En esa misma línea está la profesora Socorro, profesora del área de salud: «...hay una parte genética que es muy fuerte, que son las hormonas, que si tú tienes hormonas bastantes complejas van a corregir y dar cambios físicos, entonces te cambian. Y se hacen porque esa persona en su momento de desarrollo fue criada de acuerdo a su género y entonces él adopta eso» (1-15:01). Las teorías no necesariamente son claras ni están estructuradas; operan como heurísticos, atajos mentales que permiten dar sentido a las conductas que son juzgadas como irregulares. El profesor Jorge, de 51 años y encargado del área de ciencias humanas, presenta un elenco de teorías explicativas:

\footnotetext{
Algunos dicen que hay personas que nacen con una producción de hormonas femeninas que hace que se... genere una inclinación natural y espontánea hacia el sexo... eh... que prefiere. Pero también hay bisexuales y existe también personas que no siempre han sido homosexuales, sino que han sido heterosexuales y también por una influencia cultural o puede ser una curiosidad que hace que el cerebro organice sus patrones de conducta, no sé qué tanto... (1-5:14-6:30).
}

Para los profesores entrevistados, la diversidad sexual, específicamente la homosexualidad, se originaría en la producción desordenada de hormonas que influencia la conducta de los estudiantes, pues a partir de la producción de una hormona $u$ otra (en las entrevistas se utilizaban conceptos de hormonas «masculinizantes» o «feminizantes») se actuaría de un modo masculino o femenino. Estas teorías coinciden con la idea de que los adolescentes están llenos de tensiones internas y sus conductas buscarían desestabilizar simbólicamente el orden social por medio de cuestionamientos a la normatividad (entre ellas la búsqueda de reconocimiento de sus cuerpos y de su identificación como sujeto sexual diverso). La ecuación «adoles- 
cencia $=$ hormonas no solamente interpreta el origen de la diversidad, sino que es más amplia, pues se nutre de la idea de pérdida de control sobre el cuerpo del otro: los niños son mucho más fáciles de controlar que los adolescentes, pues en estos las hormonas han causado crisis.

La visibilización no asegura una aceptación simbólica ni un reconocimiento de la sociedad (Castelar, 2010), lo cual deriva en acciones de discriminación y silenciamiento. Algunas consecuencias de la visibilización de la homosexualidad serían positivas y otras no tanto. Según Jorge: «yo sé que para poder protegerse o defenderse, y de hecho muchos [...] transexuales han aparecido, he escuchado, han recurrido a la prostitución porque son objetos de deseo sexual muy llamativos, son seres exóticos, seres extraños, que aparecen en la sociedad, diferentes y pueden ser fácilmente comerciales» (1-12:00-12:40). De modo que la diversidad se hace presente no solamente en las orientaciones, sino en las expresiones y en los cuerpos, que son pensados como objetos de fascinación, que encarnan la novedad. Estas expresiones de diversidad son recibidas con censura y persecución; y posteriormente, acciones de exclusión en el mundo laboral (Pérez Álvarez, 2013), lo que derivaría a recurrir a la prostitución como forma de trabajo.

Estos rasgos pueden ser interpretados de modo negativo, pero también pueden ser vistos como un aspecto positivo. Dice el profesor Jairo:

...los homosexuales hombres tienden por ejemplo a una modalidad menos técnica, ahora que [en los colegios] hay una formación técnica, todos tienden a irse para allá, claro que es una gran mayoría [...] son más sensibles por el arte, son más dados a unos temas que son de tipo estético. Además son personas que tienen gran capacidad de liderazgo en asuntos del colegio, por ejemplo son buenos estudiantes, algunos impulsan proyectos alternativos o que cuando hay un proyecto alternativo se vinculan a él, tratan de buscar sitios donde se sienten [...] socialmente bien ubicados; entonces uno los ve con temas que tienen que ver con la difusión de cultura, con la música, con lo audiovisual, con asuntos comunitarios (17:40).

De este modo, el recurso del estereotipo (usualmente negativo) dirigido a la orientación sexual, como lo es manifestar afinidad por las artes plásticas en el caso de hombres homosexuales; puede ser empleado desde una mirada «positiva», atribuyéndole una mayor sensibilidad en lo artístico, en el trabajo estético (es decir, el impacto de los sentidos). Para los docentes, estas expresiones de diversidad son interpretadas como una canalización a un saber hacer o a una posible elección de vocación laboral, pero también manifestaciones que podrían alterar el statu quo de la institución. 
Lo que subyace a esta lectura del otro, sin embargo, es que esta vocación es interpretada a partir de una cierta «diversidad cerebral», reforzando el imaginario del desarrollo de identidades y estilos de vida. Las consecuencias de esta diversidad cerebral empiezan a ser notorias cuando se piensa en el uso de etiquetas naturalizadas y sus consecuencias en las relaciones y en la convivencia. ${ }^{23}$

\section{Pero ¿a quién le conviene que la diversidad sexual sea un asunto cerebral?}

Las teorías según las cuales las expresiones de diversidad (ejemplificadas por los docentes en la homosexualidad masculina) responden a fenómenos naturalizados, han proliferado en los últimos años y han sido fomentadas incluso por activistas que trabajan en pro del reconocimiento de derechos. A la larga, ha beneficiado a esta población (al menos a corto plazo) al poner en la agenda pública la discusión sobre sus necesidades diferenciadas. Como se vio en las afirmaciones de los profesores, resulta más fácil entender el impacto de la diversidad a partir de una teoría cerebral (con todo lo que ello implica). Sobre este aspecto, el investigador Roger Lancaster analiza la proliferación de teorías cerebrales sobre la diversidad sexual en estos términos:

...un número significativo de personas creen que la ciencia moderna ha demostrado la existencia de un «cerebro gay» o de un «gen gay»-sinecura contemporánea de una naturaleza interna, de una orientación sexual fija, inmutable, y la justificación científica última de eso que, sea lo que sea, está bien porque es, simplemente, «natural». (Lancaster, 2003: 234).

Ante esto, se pueden formular dos críticas de cuño diferente en términos epistemológicos: una fuerte (por ser una crítica interna a la propia teoría) y una débil (que proviene de una mirada externa a la misma).

La crítica fuerte a la teoría cerebral de la diversidad sexual se puede resumir en la pregunta: ¿cómo saber que eso que veo en la imagen cerebral, se corresponde con un proceso psíquico? Desde que existe la ciencia, este problema se ha conocido como un «reduccionismo metodológico». La novísima ciencia de las imágenes cerebra-

23. No se hará mención de las ideas de orientación cristiana, que consideran posible modificar la orientación homosexual a través de terapias de la conducta, de la oración, del cambio de vida, etc., y convertir a personas en heterosexuales o al menos evitar que aparezca en ellos un deseo homoerótico (Jones, 2012). Ello presupone que la homosexualidad se origina en el distanciamiento de Dios o incluso en posesiones de fuerzas oscuras. 
les establece conclusiones a partir de las observaciones de cambios en el cerebro, a través del uso de ondas de radio o rayos $\mathrm{X}$. Las técnicas más recientes incluyen la verificación de procesos en vivo (durante la realización de una actividad): por ejemplo, el consumo de glucosa con un marcador radiactivo en una cierta región del cerebro, permite pensar en que esa zona se activa. Sin embargo, en el cerebro no hay zonas exclusivas de funciones específicas humanas (las teorías sobre la plasticidad cerebral revelan procesos de recuperación de tejido, lo que implica recuperar funciones cognitivas). En ese sentido, como advierte Siri Hustvedt, «no creo que el carácter sutil de la subjetividad e intersubjetividad humanas pueda reducirse a las neuronas» (2013: 174) o según el historiador del psicoanálisis George Makari: «No se podía afirmar tan a la ligera que un nervio albergase una palabra o una idea» (citado por Hustvedt, 2010: 27).

Nadie consideraría hoy que una conducta humana se origina exclusivamente en el cerebro, eliminando procesos de aprendizaje o de socialización. Tal como aseveran los profesores entrevistados, el factor cerebral tiene un peso significativo, pero no está sobredeterminado por este. La pregunta puede desplazarse, entonces, a la ruta por la que se origina la conducta. Hustvedt (2010; 2013) se pregunta por el sentido de las representaciones neuronales, es decir, cómo las neuronas del cerebro representan las cosas, las ideas, etc. La respuesta es que las neuroimágenes (y en general, la ciencia) no puede buscar las respuestas a fenómenos complejos $\mathrm{y}$, por ello, debe hacerlo con elementos simples, discretos, datos que representen procesos más complejos.

Es posible pensarlo a través del concepto de «correlativo neuronal» que ella explica así: «Estoy furiosa y cuando me pongo furiosa se activan determinados circuitos neuronales de mi cerebro. Para evitar llamar furia a ese estado de excitación de las neuronas, los científicos hablan de correlativos. El lenguaje es importante» (Hustvedt, 2010: 144). De modo que la región coloreada en la neuroimagen o el área que se activa en la tomografía, se constituirían en datos que permiten inferir un proceso cognitivo, o al menos uno de sus componentes. Esta estrategia ha hecho a un lado las estrategias anatomo-patológicas de antaño, en las que se comparaban los volúmenes cerebrales de varones homosexuales y se los comparaba con patrones de personas que se declaraban heterosexuales. ${ }^{24}$ No obstante, todavía hoy se recurre a la comparación entre las dimensiones del hipotálamo o de la amígdala, que

24. Es importante notar que, en muchas de estas investigaciones, los convocados son varones homosexuales, que son comparados con los datos obtenidos con mujeres que se definen como heterosexuales, y luego cotejados con los datos de varones que se declaran como heterosexuales. De modo que la orientación sexual pasa a ser analizada en función de la diferencia naturalizada entre hombres y mujeres. 
suponen la causa por la que algunos hombres actúan de forma similar a las mujeres (Lancaster, 2003: 240 y ss.).

Pero ¿cómo inferir la diversidad sexual a partir de correlativos? Para ello sería necesario establecer un factor común a todas sus expresiones (que incluyen orientación sexual, expresión de género, identidad e incluso la conformación anatómica y fisiológica, para el caso de la intersexualidad). ¿Es así de fácil sostener que el deseo homoerótico es un objeto delimitado o un proceso discreto que reside en una zona del cerebro o en una porción de un cromosoma, alterado en comparación al cerebro de la mayoría heterosexual? ¿O que esa zona del cerebro/porción del cromosoma está alterado y por eso las personas homosexuales presentan mayores padecimientos emocionales y sociales que las personas heterosexuales (que incluirían variaciones del estado de ánimo, mayor ansiedad, tendencia al consumo de sustancias psicoactivas, ideaciones e intentos suicidas) según estadísticas correlacionales (Jones, 2012: 28; ver también los comentarios de Mauricio Rubio, octubre 22 de 2014)?

Tal como los profesores cuando opinan que la diversidad se origina en algún punto del cerebro o gracias a la liberación de cierta hormona, desde las investigaciones científicas se trata de dar sentido a lo que se considera como anómalo. Y en este punto se puede formular la segunda crítica, en este caso una crítica débil por provenir no de la misma ciencia, sino de la reflexión política, pero no por ello menos importante, y que se puede resumir en la siguiente idea: los discursos médicos y científicos contemporáneos perpetúan la idea de que la diversidad (representada por el paradigma de la homosexualidad) es una anomalía etiológicamente detectable, y aun pronosticable. Y por qué no: previsible.

Esta modalidad de trabajo, propia de disciplinas de hoy como la neuroimagenología o la sociobiología, es considerada por Lancaster como un «fetichismo heterosexual», amparado en argumentos naturalizados para sostener la norma heterosexual (o mejor, heteronormativa) y que, a la larga, opera como una estrategia de normalización que desdibuja el sentido de la ciencia:

No es accidental que las referencias a Dios, la gran criatura fetiche de las historias sobre los orígenes de Occidente, siga apareciendo en las reflexiones sobre el mundo miniaturizado de los genes sociales y virtualmente en todo reclamo que presuponga que los genes proveen el prototipo para la naturaleza humana (Lancaster, 2003: 103).

O dicho en otros términos: el objeto de interés es el varón, no la mujer, que es usada solo como punto de referencia. A ella no se la examina en estos trabajos debido a la permanente invisibilización a la que se somete la condición lesbiana y sus necesidades. 
Ya desde el siglo XIX, la psiquiatría había empezado la tarea de naturalizar la diferencia en las orientaciones, al considerar la homosexualidad como una anomalía que evidenciaba la degeneración de la especie y hacer del «paciente invertido» un objeto aislado, digno de investigación científica. Este proceso ha tenido sus consecuencias, entre ellas, la producción de una identidad reconocible a través del deseo. ${ }^{25}$

Este desplazamiento del acto al actor, llevó a que la conducta desviada fuese vista como una manifestación de una conducta fundamentalmente anormal. Ello dio origen a la idea de que una persona pudiese ser definida a partir de sus deseos eróticos y que esos deseos constituían el centro de su ser y determinaban en ellos una identidad específica que los ligaba a otros que tenían deseos similares. (Cameron y Kulick, 2003: 96). ${ }^{26}$

De este modo, se evidencia la producción del homosexual, un cierto tipo de sujeto, dócil, que es necesario que sea vigilado y estudiado por la ciencia, para conocer de qué carece frente a la norma heterosexual. Digno de estudio gracias a su anomalía reproductiva (tal como el hermafrodita de antaño, el homosexual decimonónico rechaza la descendencia como estrategia de normalización). Siguiendo a Foucault:

El homosexual del siglo XIX se convirtió en un personaje, un pasado, una historia de vida, una infancia, además de ser un tipo de vida, una forma de vida, una morfología, con una anatomía indiscreta y posiblemente con una fisiología misteriosa. Nada que estuviera en su estructura dejaba de verse afectado por su sexualidad; estaba presente en él en todas partes: en el origen de todas sus acciones [...] su sexualidad era consustancial a él; menos que un pecado habitual era una naturaleza singular. El sodomita era un relapso: el homosexual es ahora una especie. (Foucault, 1981: 57).

En este punto, el concepto de «biopolítica», acuñado por Michel Foucault (2007), puede resultar aclarador. La biopolítica es una modalidad de pensamiento político que surgió luego de la caída del Antiguo Régimen y está centrada en el control y regulación de la vida humana a través de la práctica gubernamental: los mecanismos de poder y gobierno de instituciones sociales como las políticas públicas, el ejército, las escuelas y la familia, por ejemplo.

La biopolítica ha sido, desde entonces, el arte de hacer vivir, a través del control de lo que hace que un cuerpo sea un cuerpo. En el caso de la sexualidad, este dispositivo

25. El deseo comprendido como forma de producción de agenciamiento, que puede ser dirigido y satisfecho a la nada. Para Deleuze y Guattari «no es el deseo el que se apoya sobre las necesidades, sino al contrario, son las necesidades que se derivan del deseo» (García Collado, 2013: 291).

26. Traducción propia. 
privilegió la reproducción «(que enarbola el valor de la vida) sobre el placer (que se erige en el valor de la libertad)» (Serrato y Balbuena, 2015: 157). Es por eso que la diversidad sexual es la anomalía en las instituciones escolares: en un entorno en el cual la transmisión de sentido es de carácter heteronormativo y autorregulatorio, se pone en entredicho que la sexualidad tenga como único fin la reproducción.

El dimorfismo cerebral basado en la orientación sexual opera como una estrategia biopolítica (de tantas empleadas por la medicina) que sostiene la diferencia entre lo normal y lo patológico, entre lo sano y lo enfermo y, en ese sentido, elimina la diversidad (al anular expresiones como la bisexualidad, por ejemplo). Si esta distinción se mantuvo a lo largo del siglo XIX y parte del XX fue a través de la posición de los expertos (manuales diagnósticos, pericia clínica), pero fue con la masificación de las neuroimágenes como se acentuó la necesidad de estudiar el funcionamiento cerebral y establecer los orígenes de las conductas humanas, en especial las desviadas (Rose y Abi-Rached, 2013). El siglo XX, que fue el siglo de la medicina, asistió a la medicalización galopante de la vida cotidiana: una forma de colonización discursiva que se amparó en el discurso experto y en la búsqueda de la perfectibilidad de lo humano (o al menos, de incidir en él para mejorar sus procesos):

Los conceptos neurobiológicos del ser persona no están borrando otras concepciones de lo que somos como humanos, en particular aquellos que parten de la psicología. Por el contrario, se han asegurado a ellos en muchos sitios y prácticas que fueron colonizados por la psicología a lo largo del siglo XX desde la crianza de los niños hasta el mercadeo, y los ha transformado de modo significativo. (Rose y Abi-Rached, 2013:9). ${ }^{27}$

Hoy, los saberes sobre lo cotidiano pasan de una u otra forma por las teorías cerebrales, desde las conductas delictivas hasta las enfermedades crónicas; desde las adicciones hasta las relaciones sociales. $Y$ la diversidad sexual no ha escapado a este fenómeno. Lo destacable de esta modalidad de pensamiento es que no solamente se queda en el presente sino que mira hacia el futuro.

La biopolítica, al menos desde el siglo XVIII ha estado orientada al futuro. Desde las políticas más tempranas de población, gobernar la vitalidad es un proceso que opera en un eje de tiempo y se orienta hacia el futuro, y las imágenes del futuro son intrínsecas al pensamiento y a las estrategias biopolíticas, de la política de la salud del siglo XVIII pasando por la preocupación por la degeneración de la población en el siglo XIX, hasta la aparición de la eugenesia y el nacimiento de las estrategias de los seguros de vida en la primera mitad del siglo XX. (Rose y Abi-Rached, 2013: 14). ${ }^{28}$

27. Traducción propia de los autores.

28. Traducción propia. 
La administración contemporánea de los cuerpos pasa por la difusión y el fomento de recursos discursivos que sostienen la distinción entre lo normal (operativo, funcional) y lo patológico (perturbado, anómalo, problemático) e inciden en las decisiones políticas a largo plazo (criterios en cuidados médicos, políticas en educación, sostenimiento de procesos de rehabilitación social, entre otros). La palabra clave es «prevención». Si se anticipan elementos que despiertan sospecha (conductas, situaciones anómalas, etc.), se pueden tomar ciertas medidas, sino correctivas, al menos paliativas. Y así ha funcionado la escuela, sin ir más lejos.

Uno de los profesores entrevistados consideraba que el adolescente homosexual tiende a inclinarse por lo estético, por las formas sensibles y por las estrategias de comunicación; la seducción de la imagen puede conducir, para el mismo profesor, al exotismo del trabajo sexual. Otras profesoras veían el exceso de hormonas como causante de crisis y desorden. Pero no las piensan como procesos pasajeros o formas variadas de conducta, sino como producto de un desorden genético, de una falla hormonal o de un proceso crónico que aqueja a quien la padece. El destino de las personas sigue estando atado a este rasgo, que se estudia y se compara con modelos de normalidad.

\section{A modo de conclusión: las paradojas del reconocimiento en la escuela}

Estas reflexiones tratan de crear nuevos espacios de diálogo y encuentro. Como se advirtió al inicio, el propósito ha sido caracterizar algunas paradojas que no han sido planteadas en las problemáticas escolares contemporáneas, de cara a ampliar el panorama en el tema de la convivencia. La escuela es un espacio que ha empezado a abrir sus puertas a la heterogeneidad de pensamientos, discursos y acciones, pero el reconocimiento de los docentes hacia esta diversidad se ha producido de forma un tanto agresiva, a través de prácticas modernas de control sobre los sujetos que alteran la homogeneidad escolar: aquellos con discapacidad física, con dificultades en la relación o que expresan su diversidad en lo sexual y en su género, entre otros, lo cual resulta paradójico. Y es que el cuerpo docente de hoy enfrenta una encrucijada sobre cómo actuar frente a la diversidad: el orden y la uniformidad niegan la diversidad de los cuerpos, pero el reconocimiento de la diversidad implica poner en riesgo los principios básicos de la institucionalidad, en este caso, la heterosexualidad normativa.

Otra situación paradójica está en las ideas que el maestro tiene frente a la identidad sexual de sus estudiantes. En las entrevistas se encontró que estos hacían un llamado a los referentes tradicionales de masculinidad o feminidad, y sostenían 
un modelo binario que no daba espacio para ambigüedades. Por ello, el recurso de las teorías cerebrales ha sido de utilidad para disminuir la tensión propia de estas contradicciones. El lenguaje sirve para aclarar el origen (y aún, el sentido) dado a la diversidad, pero a la vez, opera como un mecanismo de control de los cuerpos y de las subjetividades. Y dentro de ese lenguaje, los discursos científicos juegan un papel preponderante, centrados en la búsqueda heterosexual de la verdad. En un plano similar a las teorías incipientes de los profesores, los correlativos neuronales infieren una conducta (pero también suponen un deseo, un modo de vivir y de amar) a partir de rasgos aislables, bastante cuestionables.

Finalmente, es paradójico que reconocer la existencia de las formas de diversidad no sea garantía de su respeto ni de su aceptación. En el plano macro, el reconocimiento se ha articulado a procesos de clasificación de los cuerpos, y la escuela ha sido un espacio privilegiado para ello. Los profesores entrevistados todavía ven la diversidad como un fenómeno perturbador, generador de crisis y de desorden, pero para adaptarse a su presencia han incluido dentro de su elenco argumentativo las mencionadas teorías cerebrales.

De modo que las prácticas de (mal)reconocimiento de la diversidad, al estar amparadas en la diferencia radical, contribuyen a la producción de seres inferiorizados, menospreciados y sobredeterminados; por lo cual es necesario poner en crisis esta estrategia de fomento de la convivencia. La escuela no solamente puede ser pensada ni vivida en clave de producción biopolítica (que es como la ha concebido la política de hoy), centrada en la clasificación de los cuerpos y la preparación de los más aptos, sino un espacio de auténtico reconocimiento a través del encuentro de múltiples y variadas formas de vivir el cuerpo y las relaciones. Pese a que cada vez se imponen menos modelos en ese plano (al menos de forma explícita), el control del cuerpo todavía pasa por la vigilancia de la conducta heterosexualizada y por la limitación de expresiones consideradas subversivas en este plano.

Si se comprende que la crisis de la escuela actual es, antes que nada, una oportunidad de transformar y desafiar procesos de violencia institucional, podremos hablar de nuevas formas de convivencia y de encuentro con el otro. Queda abierta entonces una nueva posibilidad de reflexión sobre las tensiones y desafíos de la escuela de hoy, que no solían estar incluidos en el elenco de temáticas clásicas de la educación. 


\section{Referencias}

AVERBUJ, G.; BOZZALLA, L.; MARINA, M.; TARANTINO, G. y ZARITZKY, G. (comps.). (2005). Violencia y escuela. Propuestas para comprender y actuar. Buenos Aires: Aiqué Eds.

BEAUVOIR, S. (1949). El segundo sexo. Valencia: Ed. Cátedra.

BURMAN, E. (1994). La deconstrucción de la psicología educativa. Madrid: Visor.

BUSS, D. (1996). La evolución del deseo. Madrid: Alianza.

BUSTAMANTE, W. (2008). El delito de acceso carnal homosexual en Colombia. Entre la homofobia de la medicina psiquiátrica y el orden patriarcal legal. Co-herencia, 5(9), 113-141.

BUSTAMANTE, W. (2009) Homoerotismo y homofobia en Colombia: una visión histórica. Ponencia llevada a cabo en III Seminario Internacional sobre Familia. Manizales, Colombia.

CAMERON, D. y KULICK, D. (2003). Hablar de sexo y pensar en sexo: la lingüística y la construcción discursiva de la sexualidad. Revista La manzana de la discordia, 2(3), 93-111.

CASTELAR, A. (2010). Judith Butler y el problema del reconocimiento. En: Grueso, D. y Castellanos, G. Identidades colectivasy reconocimiento. Cali: Fondo Editorial de la Universidad del Valle.

CASTELAR, A. (2014). Diversidad sexual en el aula. Educación y ciudad, (26), 77-86.

CLARKE, V. y PEEL, E. (2007). Out in Psychology: Lesbian, Gay, Bisexual, Trans and Queer Perspectives. Hoboken: Wiley Eds.

CORTE CONSTITUCIONAL DE COLOMBIA. (1998). Sobre el régimen disciplinario para docentes yel principio de favorabilidad. [Sentencia C-481 de 1998]. Recuperado de: http://www.corteconstitucional.gov.co/relatoria/1998/c-481-98.htm

DUSCHATSKY, S. y BIRGIN, A. (2001). ¿Dónde está la escuela? Ensayos sobre la gestión institucional en tiempos de turbulencia. Buenos Aires: Eds. Flacso - Manantial.

FOUCAULT, M. (1981). Historia de la sexualidad. Tomo I: la voluntad de saber. México: Ed. Siglo XXI.

FOUCAULT, M. (2007). El nacimiento de la biopolítica. Curso en el Collège de France, 1978-1979. México: FCE.

FOUCAULT, M. (2008). Vigilary castigar; nacimiento de la prisión. Buenos Aires: Siglo XXI Editores Argentina.

FRASER, N. (1997). Iustitia Interrupta. Bogotá: Siglo del Hombre - Uniandes.

GARCÍA COLLADO, F. J. (2013). Análisis del concepto de deseo en Platón, Freud y Lacan frente a la crisis del sujeto contemporáneo (Tesis de doctorado). Universitat de Barcelona, Barcelona, España. 
GARCÍA SUÁREZ, C. I. (2007). Diversidad Sexual en la Escuela. Dinámicas pedagógicaspara enfrentar la homofobia. Bogotá: Alcaldía Mayor de Bogotá - Secretaría de Educación.

GOLDENBERG, M. (comp.). (2011). Violencia en las escuelas. Buenos Aires: Grama ediciones.

DOIN G. (dir.). (2012) . La educación prohibida [Documental]. Argentina: Eulam Producciones.

HERNÀNDEZ I DOBON, F. J. (2008). La teoría crítica de Axel Honnet y la sociología de la educación. FES Barcelona. Recuperado de: https://www.uv.es/fjhernan/Textos/soc_educacio/ FESBarcelona.pdf

HUSTVEDT, S. (2010). La mujer temblorosa o la historia de mis nervios.

HUSTVEDT, S. (2013). Vivir, pensar, mirar. Barcelona: Anagrama.

ILLICH, I. (1971). La sociedad desescolarizada. Madrid: Godot.

JONES, S. (2012). Same-sex Science. En: First Things: A Monthly Journal of Religion and Public Life (pp. 27-33).

KATCHADOURIAN, H. y LUNDE, D. (1979). Las bases de la sexualidad humana. México: FCE.

LANCASTER, R. (2003). The trouble with nature: sex in science and popular culture. Berkeley y Los Angeles: University of California Press.

MARCUSE, H. (1968). La tolerancia represiva. En: Wolff, R. et al., Crítica de la tolerancia pura. Barcelona: Editios 62.

MINISTERIO DE EDUCACIÓN NACIONAL DE COLOMBIA. (2010). Manual de Implementación de Escuela Nueva: Generalidades y Orientaciones Pedagógicas para Transición y Primer Grado (Tomo I) . Bogotá: MEN.

MINISTERIO DE EDUCACIÓN NACIONAL DE COLOMBIA. (15 de marzo del 2013). Sistema Nacional de Convivencia Escolar [Ley162O de 2013]. Recuperado de: https://www.mineducacion. gov.co/1759/articles-327397_archivo_pdf_proyecto_decreto.pdf

PASCOE, C. J. (2007). Dude, you're a Fag! Masculinity and Sexuality in High School. Los Ángeles: California UP.

PEIXOTO CALDAS, J. M.; FONSECA, L.; ALMEIDA, S. y ALMEIDA, L. (2012) Escuela y diversidad sexual - ¿Qué realidad? Educaçao em Revista, 28(3), 143-158.

PÉREZ ÁlVAREZ, A.; CORREA MONTOYA, G.; CASTAÑEDA CASTRO, W.y PLATA CHACÓN, E. (2013). Rarosy Oficios. Diversidad sexualy mundo laboral: discriminacióny exclusión. Medellín: Corporación Caribe Afirmativo. 
REBELO MARTINS, M.; HERNÀNDEZ, F. J.y HERZOG, B. (2017). La sociología de la educación y la teoría del reconocimiento de Axel Honneth. Revista de la Asociación de Sociología de la Educación, 10(1), 80-89.

RENAU, M. D. (1998). ¿Otra psicología en la escuela? Un enfoque institucional y comunitario. Barcelona: Paidós.

RENOLD, E. (2005). Girls, Boys and Junior Sexualities. Exploring Children's Gender and Sexual Relations in the Primary School. Londres: Falmer Press.

REYES, W. H. (2013). Reflexiones psicoanalíticas sobre la educación: la relación entre sus actores implicados. Abordajes psicoanalíticos a inquietudes sobre la subjetividad II. Cali, Colombia: Editorial Bonaventuriana.

RICH, A. (1980). Compulsory Heterosexuality and Lesbian Existence. Signs: Journal of Women in Culture and Society, (5), 631-6o.

ROSE, N. y ABI-RACHED, J. (2013). Neuro: the New Brain Sciences and the Management of the Mind. Princeton: Princeton University Press.

RUBIO, M. (22 de octubre de 2014). Los gais se suicidan más. El Espectador. Recuperado de: http:// www.elespectador.com/opinion/los-gays-se-suicidan-mas-columna-523584

SERGIO SÍ FUE DISCRIMINADO. (25 de septiembre de 2014). El Espectador. Recuperado de: http://www.elespectador.com/noticias/bogota/sergio-si-fue-discriminado-articulo-518756

SENTIIDO y COLOMBIA DIVERSA. (2016). Mi voz cuenta: encuesta de clima escolar LGBT en Colombia. Recuperado de: http://colombiadiversa.org/colombiadiversa2016/wp-content/ uploads/2016/11/IAE-Colombia-Web-FINAL-2.pdf

SERRATO GUZMÁN, A. N. y BALBUENA BELLO, R. (2015). Calladito y en la oscuridad. Heteronormatividad y clóset, los recursos de la biopolítica. Culturales, III(2), 151-180. 